\title{
Short communication: Automated detection of behavioral changes from respiratory disease in pre-weaned calves
}

\author{
T. H. Swartz, ${ }^{*}$ A. N. Findlay, † and C. S. Petersson-Wolfe ${ }^{* 1}$ \\ *Department of Dairy Science, and \\ †Department of Biological Sciences, Virginia Tech, Blacksburg 24061
}

\begin{abstract}
Group housing of calves can pose a challenge in identifying respiratory disease; therefore, it is necessary to develop tools that can identify these disease events. In this experiment, pre-weaned calves $(\mathrm{n}=30)$ were housed in groups with an automatic calf feeder and were fitted with an accelerometer. Step activity, lying behaviors, and feeding behaviors were recorded to determine the effect of respiratory disease. All calves were health scored twice daily, and calves with respiratory scores $\geq 5$ were diagnosed with respiratory disease $(\mathrm{n}=$ 10). Each diseased calf was match paired with a healthy control based on the date of disease diagnosis, breed, and age. Control calves were determined to be healthy if they had respiratory scores $\leq 4$, as well as fecal, navel, and joint scores of 0 or 1 . Diseased calves were less active before, on the day of, and after respiratory disease diagnosis. Furthermore, diseased calves had reduced lying frequencies starting $2 \mathrm{~d}$ before diagnosis, as well as after diagnosis. Last, diseased calves consumed less milk on the day of diagnosis when compared with healthy controls. Step activity, lying bouts, and milk intake may prove to be a useful tool in identifying respiratory disease under practical farming, but this requires further research.
\end{abstract}

Key words: calf, respiratory disease, activity, feeding behavior

\section{Short Communication}

The use of automatic calf feeders in pre-weaned calves is gaining popularity as dairy producers look to reduce labor costs and improve calf welfare (Kung et al., 1997). Automatic calf feeders allow for calves to consume greater daily intakes of milk spread over more meals than traditional feeding systems. High milk intake diets have been positively correlated with increased growth rates and first lactation milk yield

Received November 8, 2016.

Accepted June 22, 2017.

${ }^{1}$ Corresponding author: cspw@vt.edu
(Soberon et al., 2012). Group- and pair-housing of preweaned calves has demonstrated additional benefits including an increase in concentrate intake, and ADG, with these increases culminating in the weaning period (Miller-Cushon and DeVries, 2016; Pempek et al., 2016). Furthermore, pair-housed calves have improved social abilities, were less fearful (Duve et al., 2012), and adapted to environmental changes more quickly when compared with individually housed calves (Gaillard et al., 2014), providing evidence that individualhousing impairs social as well as cognitive performance. Although there are numerous benefits of group-housed calves on an automatic calf feeder, large group sizes are associated with increased risk for respiratory disease and difficulties in identifying diseased calves when compared with individually housed calves (Svensson et al., 2003; Svensson and Jensen, 2007). Mortality associated with respiratory disease in pre-weaned calves is $22.5 \%$ (USDA-APHIS, 2007). Therefore, the development of technologies to aid in the identification of this disease is warranted.

Several methods of respiratory disease detection in calves currently exist, from health examinations (McGuirk, 2008), to approach tests with either a human or a novel object (Cramer and Stanton, 2015), and automated technologies such as noninvasive infrared thermography (Schaefer et al., 2012). Although these methods have merit, daily examinations may be time consuming and could require additional labor. Furthermore, noninvasive infrared thermography may not be economically feasible for all farms. Therefore, alternative methods of respiratory disease detection may be needed. Some farms may already be utilizing an automatic calf feeder to reduce labor costs; thus, maximizing the use of the data from these feeders for respiratory disease detection may provide additional value. Other farms may already be utilizing accelerometers in adult cattle for heat detection (Dolecheck et al., 2015) and disease detection (Rutten et al., 2013); however, these accelerometers may also prove valuable for disease detection in calves (Trénel et al., 2009).

Past research studies have examined feeding behavior around disease events in pre-weaned calves. Svensson 
and Jensen (2007) found restrictively fed diseased calves have fewer unrewarded visits when compared with healthy restrictively fed calves; however, no difference was seen for drinking speed, milk consumption, and rewarded visits. Another study found that diseased calves on a high milk allowance demonstrated fewer total visits, reduced milk intake, and an increase in visit duration when compared with healthy calves; conversely, when examining calves on a low milk allowance, sick calves demonstrated a reduction in visit duration and no difference was noted for milk intake and total visits (Borderas et al., 2009). Another study, using an experimentally induced pneumonia design, showed a reduction in step activity $24 \mathrm{~h}$ postinoculation of Mannheimia haemolytica when compared with negative controls (Hanzlicek et al., 2010).

Previous studies have examined the effect of multiple diseases on feeding behavior (Svensson and Jensen, 2007; Borderas et al., 2009). Because behaviors may differ between diseases, it could be useful to examine the effect of each disease separately. Furthermore, because milk allowances will vary from farm to farm, using additional tools may have value in detecting disease in pre-weaned calves to complement feeding behavior. Therefore, the aim of this study was to assess the changes in feeding behavior as well as step activity and lying behaviors in pre-weaned dairy calves before and during the onset of respiratory disease. We hypothesized that diseased calves would be less active and would, therefore, spend more time lying around the time of respiratory disease onset than healthy calves. Furthermore, we hypothesized that diseased calves would consume less milk at a slower drinking speed, and have fewer total visits around the time of respiratory disease onset when compared with healthy calves.

This study was conducted from March 2016 through August 2016 at the Virginia Tech dairy in Blacksburg, in accordance with guidelines set by the Institutional Animal Care and Use Committee (16-002).

Female Holstein and Jersey calves $(\mathrm{n}=30$; 19 Holstein and 11 Jersey) were enrolled in this trial at birth, moved into individual hutches, ear tagged, and fed $4 \mathrm{~L}$ of colostrum after birth. Calves remained in individual hutches for the first $6 \mathrm{~d}$ of life. While in hutches, calves were fed $2 \mathrm{~L}$ of $40.6^{\circ} \mathrm{C}$ water mixed with $300 \mathrm{~g}$ of milk replacer (Cow's Match, Warm Front PB, Land O'Lakes Animal Milk Products Co., Shoreview, MN) twice daily.

When the calf was $7 \mathrm{~d}$ of age, calves were moved into group-housing with an automatic calf feeder (FA Förster-Technik GmbH, Engen, Germany). The pen had a $6.3 \times 6.0 \mathrm{~m}$ bedded pack and a $4.3 \times 6.0 \mathrm{~m}$ concrete alley that were maintained by the farm staff. To reflect what occurs on most dairy farms, group size was dynamic; calves entered group housing $7 \mathrm{~d}$ after birth and left at weaning, $55 \mathrm{~d}$ of age. The automatic calf feeder gradually increased milk allowances from 6 $\mathrm{L}$ to a maximum of $12 \mathrm{~L}$ of milk per day; maximum milk allowance was reached when calves were $16 \mathrm{~d}$ of age. Weaning began at $46 \mathrm{~d}$ of age until $55 \mathrm{~d}$ of age when calves were weaned and removed from the pen. Calves were allowed ad libitum access to water and calf starter (Intensity 22\% Textured Calf Starter Medicated, Southern States, Richmond, VA). Water was provided through an automatic waterer (WaterMatic 150, Ritchie Industries Inc., Conrad, IA), and grain was provided in a metal feed bunk. Grain refusals were discarded daily, and new grain was provided to ensure ad libitum access. No other feedstuff was provided.

Previously validated accelerometers (AfiTag II, AfiMilk Ltd., Kibbutz Afikim, Israel) on dairy calves were attached to the calves' right rear legs at birth to collect step activity and lying behaviors (Swartz et al., 2016). These variables were collected wirelessly every $15 \mathrm{~min}$ and transmitted to a computer (AfiAct II, Afimilk LTD., Kibbutz Afikim, Israel). Data were then summarized into daily steps (no./d), lying time ( $\mathrm{min} / \mathrm{d}$ ), and lying bouts (no./d) using Excel spreadsheets (Microsoft Corp., Redmond, WA). From $7 \mathrm{~d}$ through $55 \mathrm{~d}$ of age, the automatic calf feeder recorded milk intake $(\mathrm{mL} / \mathrm{d})$, drinking speed $(\mathrm{mL} / \mathrm{min})$, as well as rewarded and unrewarded visits (no./d) for each calf. The automatic calf feeder continuously records and calculates feeding behavior data in spreadsheets using a commercial software program marketed with the feeder (Institute Software, FA Förster-Technik GmbH, Engen, Germany).

All calves were health scored twice daily (0800 and $1600 \mathrm{~h}$ ) using the Calf Health Scorer app (University of Wisconsin, School of Veterinary Medicine) until weaning. This app closely follows the criteria of the calf health scoring chart previously developed by Sheila McGuirk (McGuirk, 2008). A description of this scoring system is provided in Table 1. Calves were scored on eye discharge, ear disposition, nasal discharge, coughing, and temperature for respiratory scoring, with scores of 0 representing normal and 3 being severely abnormal. Respiratory disease was indicated when the sum of these 5 variables were $\geq 5$, provided that at least 2 of the 5 variables were $\geq 2$ (McGuirk, 2008). Calves diagnosed with respiratory disease were treated with a single subcutaneous injection of an antibiotic, tulathromycin, using label recommendations (Draxxin, Zoetis Inc., Kalamazoo, MI). Fecal consistency as well as joint and navel scores were performed to ensure that calves diagnosed with respiratory disease were only affected by respiratory disease.

For each diseased calf, a healthy calf on the same date, of the same breed, and similar age (age: mean \pm SD; healthy calves: $29.1 \pm 6.4 \mathrm{~d}$; diseased calves: 33.1 
$\pm 8.8 \mathrm{~d}$ ) was identified as the matched pair. Day 0 was assigned as the day when respiratory disease was first diagnosed with a respiratory score of $\geq 5$. Healthy controls were defined as calves with fecal, joint, and navel scores of a 1 or 0 , and a total respiratory score of $\leq 4$. Furthermore, a healthy control calf was required to maintain the above health scores for $7 \mathrm{~d}$ on both sides of d 0 (d -7 to 7 ) of its matched diseased calf. A healthy calf was eligible to serve as a control more than once; however, no control calf was used more than twice. A diseased calf was defined as a calf with a respiratory score $\geq 5$, with fecal, joint, and navel scores of a 1 or 0 . Diseased calves were required to maintain fecal, joint, and navel scores of a 1 or 0 for $7 \mathrm{~d}$ on both sides of $\mathrm{d} 0$ (d -7 to 7 ). This was done to ensure that that diseased calves were only affected by respiratory disease, and no other disease events. Of the 30 calves, 14 calves were diagnosed with respiratory disease. Four of these calves were excluded either due to the absence of an appropriate control calf $(\mathrm{n}=3)$ or the disease event occurring outside of the maximum milk allowance period $(\mathrm{n}=$ 1). Thus, only data from respiratory disease events occurring during maximum milk allowance periods were included in the analyses.

The residuals were analyzed for outliers and normality. No outliers were identified, and no data were missing. Therefore, for each dependent variable, a total of 140 observations were divided over $7 \mathrm{~d}$ and 10 pairs of calves. A repeated-measures mixed model (PROC GLIMMIX, SAS ver. 9.4, SAS Institute Inc., Cary, NC) was used with health status, day (repeated measure), and the interaction of day and health status as fixed components, and the matched pair of calves and the interaction of pair and health status as random components. All variables were modeled with the autoregressive covariance structure, and the Kenward-Roger procedure was used for degrees of freedom approximation (Kenward and Roger, 1997). Table 2 provides $F$-values, probability levels, and degrees of freedom of fixed effects. When the interaction term of day and health status was $P<0.50$, the effect of health status was compared at each day using the SLICE option in SAS. Significance was declared when $P \leq 0.05$. Daily steps (no./d) and lying bouts (no./d) for diseased and healthy calves are shown in Figure 1. Daily milk intake $(\mathrm{mL} / \mathrm{d})$ for diseased and healthy calves is shown in Figure 2. Means $( \pm \mathrm{SE})$ are also provided for each day in Supplemental Table S1 (https://doi.org/10.3168/jds .2016-12280).

Diseased calves took fewer steps than healthy controls on $\mathrm{d}-1$ (healthy vs. diseased: $2,617 \pm 184.9$ vs. $2,091.8 \pm 184.9$ steps $\left./ \mathrm{d} ; F_{1,70}=6.34, P=0.01\right)$ and on d 0 (healthy vs. diseased: $2,478.4 \pm 184.9$ vs. $1,740 \pm 184.9$ steps $/$ d; $\left.F_{1,70}=12.54, P<0.01\right)$. After medical treatment, the difference between healthy and diseased calves was diminished, with diseased calves being less active on $\mathrm{d} 1$ (healthy vs. diseased: 2,384.7 \pm 184.9 vs. $1,918 \pm 184.9$ steps $/ \mathrm{d} ; F_{1,70}=5.01, P=$ 0.03 ), d 2 (healthy vs. diseased: $2,568.6 \pm 184.9$ vs. $2,129.2 \pm 184.9$ steps $\left./ \mathrm{d} ; F_{1,70}=4.44, P=0.04\right)$, and d 3 (healthy vs. diseased: $2,789.9 \pm 184.9$ vs. $2,286.3 \pm$ 184.9 steps $\left./ \mathrm{d} ; F_{1,70}=5.83, P=0.02\right)$.

Table 1. Definitions of the scoring system used to determine disease status adapted from the Calf Health Scorer app (University of Wisconsin, School of Veterinary Medicine)

\begin{tabular}{|c|c|c|c|c|}
\hline Item & 0 & 1 & 2 & 3 \\
\hline Ear disposition & Normal & Ear flick or head shake & One ear with a slight droop & $\begin{array}{l}\text { Both ears droop, severe } \\
\text { head tilt, or both }\end{array}$ \\
\hline Coughing & No coughing & Single induced cough & $\begin{array}{l}\text { Induced multiple coughs or } \\
\text { occasional spontaneous cough }\end{array}$ & $\begin{array}{l}\text { Repeated spontaneous } \\
\text { coughs }\end{array}$ \\
\hline $\begin{array}{l}\text { Rectal temperature }\left({ }^{\circ} \mathrm{C}\right) \\
\text { Fecal scoring }\end{array}$ & 37.8 to 38.2 & 38.3 to 38.8 & 38.9 to 39.4 & Greater than 39.4 \\
\hline Fecal consistency & Normal & Pasty, semi-formed & $\begin{array}{l}\text { Loose, but remains on top of } \\
\text { the bedding }\end{array}$ & $\begin{array}{l}\text { Watery, sifts through the } \\
\text { bedding }\end{array}$ \\
\hline Joint scoring & Normal & $\begin{array}{l}\text { Slight swelling, no pain } \\
\text { or warmth }\end{array}$ & $\begin{array}{l}\text { Swelling with pain, some } \\
\text { lameness }\end{array}$ & $\begin{array}{l}\text { Swelling with severe } \\
\text { pain, heat, and lameness }\end{array}$ \\
\hline
\end{tabular}


Table 2. F-value and probability level for the effect of day, health status, and the interaction of day and health status on step activity (no./d), lying bouts (no./d), and milk intake $(\mathrm{mL} / \mathrm{d})$

\begin{tabular}{|c|c|c|c|c|c|c|c|}
\hline Source & Numerator $\mathrm{df}^{1}$ & \multicolumn{2}{|c|}{ Steps $^{2}$} & \multicolumn{2}{|c|}{ Lying bouts ${ }^{2}$} & \multicolumn{2}{|c|}{ Milk intake ${ }^{3}$} \\
\hline Health status & 1 & 15.36 & $<0.01$ & 9.20 & $<0.01$ & 0.11 & 0.74 \\
\hline Day $\times$ health status & 6 & 0.94 & 0.47 & 3.49 & $<0.01$ & 1.15 & 0.34 \\
\hline
\end{tabular}

${ }^{1}$ For random components, numerator $\mathrm{df}=9,9$, and 108 for pair, pair $\times$ health status, and the residual, respectively.

${ }^{2}$ Denominator $\mathrm{df}=20,97$, and 97 for health status, day, and day $\times$ health status, respectively, for both steps and lying bouts. Denominator $\mathrm{df}$ approximated using the Kenward-Roger method.

${ }^{3}$ Denominator $\mathrm{df}=30,103$, and 103 for health status, day, and day $\times$ health status, respectively, for milk intake. Denominator $\mathrm{df}$ approximated using the Kenward-Roger method.

No difference in lying time was observed. However, diseased calves had a reduction in lying frequency on d -2 (healthy vs. diseased: $26.9 \pm 1.95$ vs. $22.6 \pm 1.95$
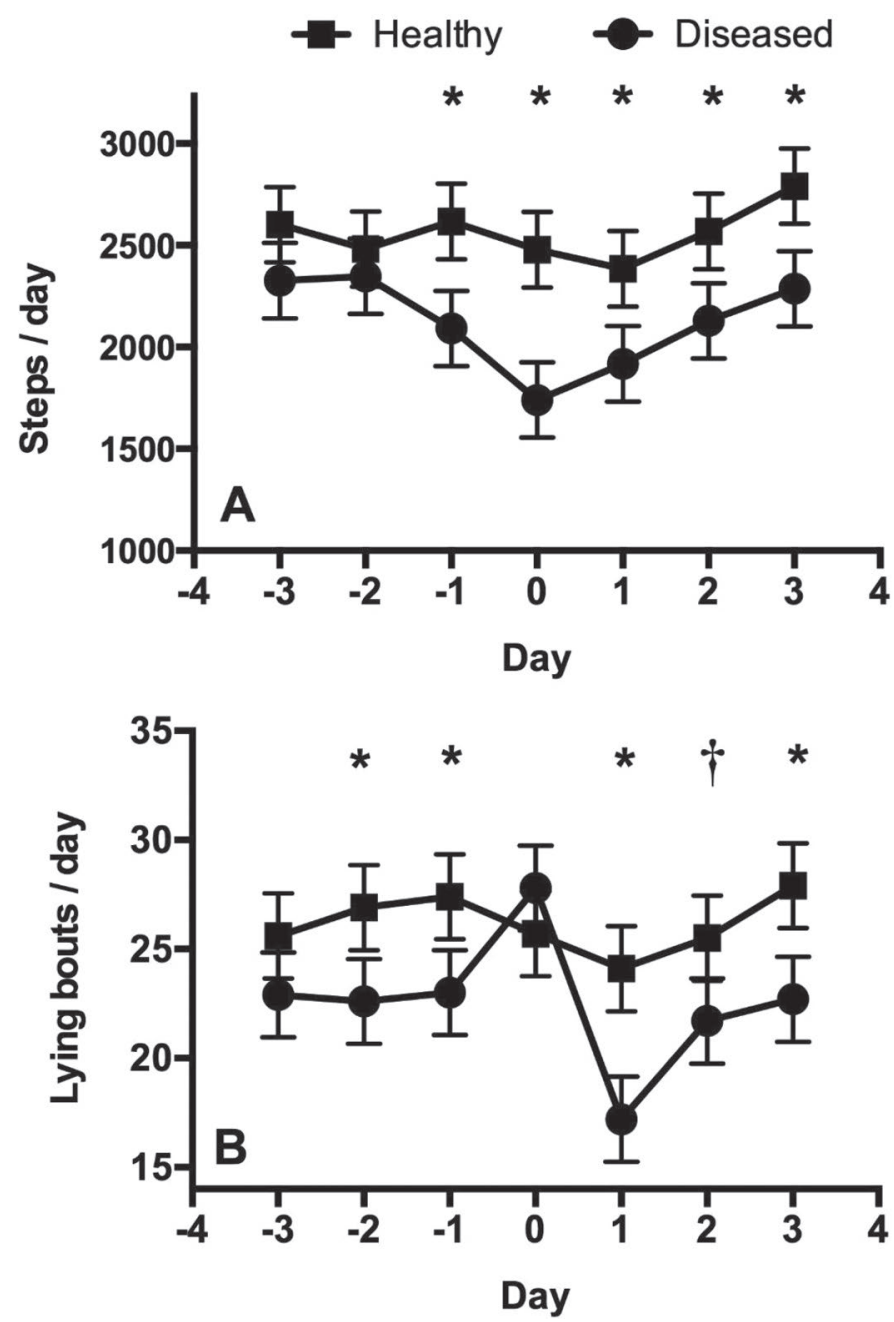

Figure 1. Mean $( \pm \mathrm{SE})$ for daily steps $(\mathrm{A})$ and lying bouts $(\mathrm{B})$ of diseased and healthy calves at each day (with d 0 representing the day respiratory disease was first diagnosed). Differences between healthy and diseased calves: ${ }^{*} P \leq 0.05, \dagger P<0.10$. lying bouts $\left./ \mathrm{d} ; F_{1,69}=4.04, P=0.05\right), \mathrm{d}-1$ (healthy vs. diseased: $27.4 \pm 1.95$ vs. $23.0 \pm 1.95$ lying bouts $/ \mathrm{d}$; $F_{1,69}=4.23, P=0.04$ ), d 1 (healthy vs. diseased: 24.1 \pm 1.95 vs. $17.2 \pm 1.95$ lying bouts $/ \mathrm{d} ; F_{1,69}=10.39, P$ $<0.01$ ), and d 3 (healthy vs. diseased: $27.9 \pm 1.95$ vs. $22.7 \pm 1.95$ lying bouts $\left./ \mathrm{d} ; F_{1,69}=5.90, P=0.02\right)$ when compared with healthy controls.

No difference in milk intake was observed on $\mathrm{d}-1$ (healthy vs. diseased: $8,647.2 \pm 580.2$ vs. $7,793.2 \pm$ $580.2 \mathrm{~mL} / \mathrm{d} ; F_{1,96}=1.08 ; P=0.30$ ); however, a significant difference was observed on d 0 (healthy vs. diseased: $8,863.9 \pm 580.2$ vs. $7,261.7 \pm 580.2 \mathrm{~mL} / \mathrm{d}$; $\left.F_{1,96}=3.81, P=0.05\right)$ with diseased calves consuming approximately $1.6 \mathrm{~L}$ less milk when compared with healthy controls. No difference was found for total visits, rewarded visits, and drinking speed, or in any feeding behavior after medical treatment (after d 0).

Calves with respiratory disease were less active, had fewer lying bouts, and consumed less milk around

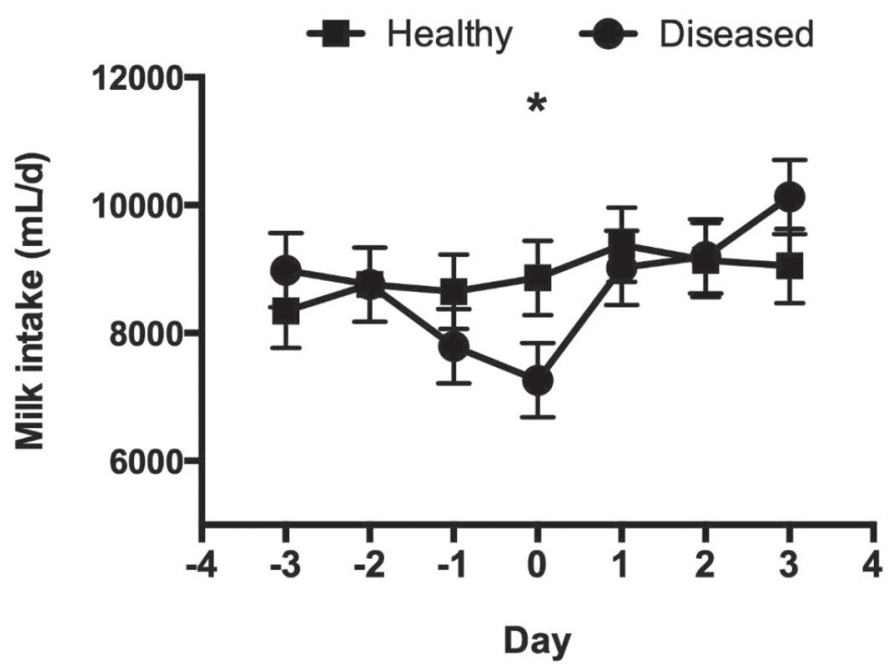

Figure 2. Mean $( \pm \mathrm{SE})$ for milk intake of diseased and healthy calves at each day (with $\mathrm{d} 0$ representing the day respiratory disease was first diagnosed). Differences between healthy and diseased calves: ${ }^{*} P \leq 0.05$. 
the time of diagnosis compared with healthy calves. These differences were most apparent on the day before and the day of diagnosis. A previous study found a reduction in steps during the 24-h period after experimentally inducing pneumonia (Hanzlicek et al., 2010). In the current study, step activity declines $1 \mathrm{~d}$ before clinical signs of respiratory disease, and on the day of diagnosis in naturally occurring respiratory disease events, with a smaller difference still noted posttreatment. Additionally, lying bouts began to decrease $2 \mathrm{~d}$ before diagnosis, as well as after diagnosis; however, no difference was seen on the day of diagnosis. In the present trial, calves diagnosed with respiratory disease were treated with tulathromycin (Draxxin, Zoetis Inc.) on the day of diagnosis. In a safety study, calves treated with tulathromycin displayed transient pain behaviors such as head shaking and pawing at the ground following administration (Zoetis, 2014). In a past research study examining pain management following castration of calves, an increase in lying bouts was associated with pain (Olson et al., 2016). In the present study, a lack of difference in lying bouts between diseased calves and controls on d 0 was observed. This could be due to transient pain from tulathromycin administration that caused an increase in lying frequency in diseased calves.

Previous research examined the effect of disease on feeding behavior (Svensson and Jensen, 2007; Borderas et al., 2009). Borderas et al. (2009) found that diseased calves on a high milk allowance (12 L/d or ad libitum) consumed less milk in fewer visits, whereas Svensson and Jensen (2007) found a reduction in unrewarded visits, but no difference in milk intake in calves fed restrictively $(5.6$ to $8.5 \mathrm{~L} / \mathrm{d})$. In the present study, only respiratory disease events that occurred during the high milk allowance period were used. Our findings were in agreement with Borderas et al. (2009), as diseased calves on a high milk allowance in the present study consumed less milk on the day of diagnosis when compared with healthy controls. However, in contrast to previous studies, no difference was found in total visits or rewarded visits. Previous studies clinically examined calves for disease during the first 3 to 4 wk of age (Svensson and Jensen, 2007; Borderas et al., 2009). In this study, calves were examined until weaning (d 55), with the average respiratory disease event occurring at $33.1 \pm 8.8 \mathrm{~d}$ (age: mean $\pm \mathrm{SD}$ ). It is possible that the effect of disease on visit frequency is limited to the first few weeks of age, or potentially to diseases other than respiratory events. The lack of difference found in feed intake after medical treatment suggests that the administration of tulathromycin restores appetite back to normal levels.

In diseased animals, behaviors that are associated with health benefits, such as play and exploratory behavior (Jensen et al., 1998; Cramer and Stanton, 2015; Cramer et al., 2016), are typically the first to decline, as sick animals divert resources from less critical functions to those that are essential for life (Weary et al., 2009). Play and exploratory behavior were not specifically measured in the current study; however, it is likely that the reduction in step activity is a result of diseased calves having less motivation to express play and exploratory behaviors (de Passillé et al., 2010). It should also be noted that feeding behaviors did not display any differences before d 0. Furthermore, milk intake returned to normal levels more quickly after medical treatment (d 0) than activity. Because activity displays differences before $\mathrm{d} 0$ and after $\mathrm{d} 0$, it appears that sickness behavior is more accentuated in activity than in feed intake. This may be due to the critical role of feeding behaviors in life functions, whereas activity is a behavior that is less essential for life, and therefore, more apt to decline when an animal is diseased.

In conclusion, calves with respiratory disease were less active, had reduced lying frequencies, and consumed less milk than healthy controls before or during the day of diagnosis. After treatment, milk intake of diseased calves returned to normal levels; however, a difference was still noted in activity and lying bouts. Future research is needed to test the ability of these technologies to identify disease prospectively.

\section{ACKNOWLEDGMENTS}

The authors recognize H. Schramm (Virginia-Maryland College of Veterinary Medicine, Blacksburg, VA) for her veterinary medicine knowledge, M. McGilliard (Department of Dairy Science, Virginia Tech) for his statistical expertise, C. Henderson (Department of Dairy Science, Virginia Tech) for her calf management assistance, and the farm staff at the Virginia Tech dairy facility for their support.

\section{REFERENCES}

Borderas, T. F., J. Rushen, M. A. G. von Keyserlingk, and A. M. B. de Passillé. 2009. Automated measurement of changes in feeding behavior of milk-fed calves associated with illness. J. Dairy Sci. 92:4549-4554.

Cramer, M. C., T. L. Ollivett, and A. L. Stanton. 2016. Associations of behavior-based measurements and clinical disease in preweaned, group-housed dairy calves. J. Dairy Sci. 99:7434-7443.

Cramer, M. C., and A. L. Stanton. 2015. Associations between health status and the probability of approaching a novel object or stationary human in preweaned group-housed dairy calves. J. Dairy Sci. 98:7298-7308.

de Passillé, A. M., M. B. Jensen, N. Chapinal, and J. Rushen. 2010. Technical note: Use of accelerometers to describe gait patterns in dairy calves. J. Dairy Sci. 93:3287-3293.

Dolecheck, K. A., W. J. Silvia, G. Heersche Jr., Y. M. Chang, D. L. Ray, A. E. Stone, B. A. Wadsworth, and J. M. Bewley. 2015. Behavioral and physiological changes around estrus events identified 
using multiple automated monitoring technologies. J. Dairy Sci. 98:8723-8731.

Duve, L. R., D. M. Weary, U. Halekoh, and M. B. Jensen. 2012. The effects of social contact and milk allowance on responses to handling, play, and social behavior in young dairy calves. J. Dairy Sci. 95:6571-6581.

Gaillard, C., R. K. Meagher, M. A. von Keyserlingk, and D. M. Weary. 2014. Social housing improves dairy calves' performance in two cognitive tests. PLoS One 9:e90205.

Hanzlicek, G. A., B. J. White, D. Mosier, D. G. Renter, and D. E. Anderson. 2010. Serial evaluation of physiologic, pathological, and behavioral changes related to disease progression of experimentally induced Mannheimia haemolytica pneumonia in postweaned calves. Am. J. Vet. Res. 71:359-369.

Jensen, M. B., K. S. Vestergaard, and C. C. Krohn. 1998. Play behaviour in dairy calves kept in pens: the effect of social contact and space allowance. Appl. Anim. Behav. Sci. 56:97-108.

Kenward, M. G., and J. H. Roger. 1997. Small sample inference for fixed effects from restricted maximum likelihood. Biometrics 53:983-997.

Kung, L., Jr., S. Demarco, L. N. Siebenson, E. Joyner, G. F. Haenlein, and R. M. Morris. 1997. An evaluation of two management systems for rearing calves fed milk replacer. J. Dairy Sci. 80:2529-2533.

McGuirk, S. M. 2008. Disease management of dairy calves and heifers. Vet. Clin. North Am. Food Anim. Pract. 24:139-153.

Miller-Cushon, E. K., and T. J. DeVries. 2016. Effect of social housing on the development of feeding behavior and social feeding preferences of dairy calves. J. Dairy Sci. 99:1406-1417.

Olson, M. E., B. Ralston, L. Burwash, H. Matheson-Bird, and N. D. Allan. 2016. Efficacy of oral meloxicam suspension for prevention of pain and inflammation following band and surgical castration in calves. BMC Vet. Res. 12:102.

Pempek, J. A., M. L. Eastridge, S. S. Swartzwelder, K. M. Daniels, and T. T. Yohe. 2016. Housing system may affect behavior and growth performance of Jersey heifer calves. J. Dairy Sci. 99:569-578.
Rutten, C. J., A. G. J. Velthuis, W. Steeneveld, and H. Hogeveen. 2013. Invited review: Sensors to support health management on dairy farms. J. Dairy Sci. 96:1928-1952.

Schaefer, A. L., N. J. Cook, C. Bench, J. B. Chabot, J. Colyn, T. Liu, E. K. Okine, M. Stewart, and J. R. Webster. 2012. The noninvasive and automated detection of bovine respiratory disease onset in receiver calves using infrared thermography. Res. Vet. Sci. 93:928-935.

Soberon, F., E. Raffrenato, R. W. Everett, and M. E. Van Amburgh 2012. Preweaning milk replacer intake and effects on long-term productivity of dairy calves. J. Dairy Sci. 95:783-793.

Svensson, C., and M. B. Jensen. 2007. Short communication: Identification of diseased calves by use of data from automatic milk feeders. J. Dairy Sci. 90:994-997.

Svensson, C., K. Lundborg, U. Emanuelson, and S. O. Olsson. 2003 Morbidity in Swedish dairy calves from birth to 90 days of age and individual calf-level risk factors for infectious diseases. Prev. Vet. Med. 58:179-197.

Swartz, T. H., M. L. McGilliard, and C. S. Petersson-Wolfe. 2016. Technical note: The use of an accelerometer for measuring step activity and lying behaviors in dairy calves. J. Dairy Sci. 99:91099113.

Trénel,, P., M. B. Jensen, E. L. Decker, and F. Skjoth. 2009. Technical note: Quantifying and characterizing behavior in dairy calves using the IceTag automatic recording device. J. Dairy Sci. 92:3397-3401.

USDA-APHIS. 2007. Heifer calf health and management practices on U.S. dairy operations, 1991-2007. National Animal Health Monitoring System, Animal and Plant Health Inspection Service and Veterinary Services, Fort Collins, CO.

Weary, D. M., J. M. Huzzey, and M. A. von Keyserlingk. 2009. Boardinvited review: Using behavior to predict and identify ill health in animals. J. Anim. Sci. 87:770-777.

Zoetis. 2014. Tulathromycin injection package insert-Draxxin. Accessed Apr. 21, 2017. https://www.zoetisus.com/products/pages/ draxxindairy/documents/draxxin-marketing-pi.pdf. 